\title{
Diagnóstico situacional de las modalidades y \\ destinos turísticos del cantón Pedro Vicente Maldonado, provincia de Pichincha
}

\section{Situational diagnosis of the modalities and tourist destinations of Pedro Vicente Maldonado canton, province Pichincha}

\author{
Diana Enríquez ${ }^{*}$, Alisson Carabalí1 ${ }^{1}$ Nadia Males ${ }^{1}$, Karen Montenegro $^{1}$ \\ 凶 Autor para correspondencia:deenriquez@uce.edu.ec \\ ${ }^{1}$ Universidad Central del Ecuador. Facultad de Ciencias Agrícolas. Carrera de Turismo. Jerónimo Leiton y Av. La Gasca s/n. Ciudadela \\ Universitaria. Quito. 170521. Ecuador.
}

\begin{abstract}
Resumen
La investigación permite establecer un diagnóstico actualizado de la actividad turística en el cantón Pedro Vicente Maldonado, en el que existe una disyuntiva en la planificación estratégica en cuanto a la modalidad de turismo más adecuada a ejecutarse, según las condiciones del lugar. Esta investigación utiliza el paradigma emergente considerando el método mixto para el estudio del sistema turístico y sus subsistemas, cada uno analizado a través de herramientas técnicas, para establecer el potencial turístico del lugar y poder definir una línea de acción adecuada que permita el desarrollo turístico de la localidad.
\end{abstract}

Palabras clave: sistema turístico, modalidad turística, diagnóstico turístico, visitante, Ecuador.

\begin{abstract}
This research allows for an updated diagnosis of tourism activity in the Pedro Vicente Maldonado canton, in which there is a dilemma in strategic planning as to the most appropriate type of tourism to be implemented, according to its conditions. This research uses the emerging paradigm considering the mixed method for the analysis of the tourist system and its subsystems. Each subsystem was analyzed through technical tools, to establish the tourism potential and to define an adequate line of action that allows the local tourism development.
\end{abstract}

Keywords: tourism system, type of tourism, diagnosis of tourism, visitor, Ecuador. 


\section{Introducción}

La provincia de Pichincha se encuentra ubicada al norte del país, en la región geográfica conocida como los Andes. Dentro de su territorio se encuentra el cantón Pedro Vicente Maldonado (PVM), caracterizado por tener gran riqueza natural, amplia extensión de tierra fecunda, clima tropical y varios ecosistemas naturales en los cuales habitan diversas especies de flora y fauna (Gobierno Autónomo Descentralizado de Pedro Vicente Maldonado, 2015).

A pesar de la gran riqueza natural del sector, el turismo como actividad económica no tiene mayor representatividad y no ha logrado desarrollarse de manera exitosa. De acuerdo a la planificación gubernamental se debe establecer una modalidad de turismo para, de acuerdo a la misma, realizar la planeación necesaria en este sector. Cabe destacar que según el Plan de Desarrollo y Ordenamiento Territorial de Pedro Vicente Maldonado (2015) el eje estratégico potencial es el turismo de aventura y deportes extremos. Por otro lado, según las entrevistas realizadas para este trabajo, la actual administración (2019) considera al turismo religioso como un producto potencial para el aprovechamiento turístico. Esta discrepancia administrativa no ha permitido que se ejecuten los respectivos proyectos que pongan en marcha el desarrollo turístico. A través de esta investigación se pretende despejar esta interrogante mediante un diagnóstico turístico. Las posibles causas de este problema son: la escasa planificación territorial, la carencia de estrategias de desarrollo definidas desde las autoridades, el inadecuado desarrollo de empresas turísticas, la idiosincrasia de los lugareños y la poca proyección con respecto al uso de los recursos naturales.

La importancia de esta investigación radica en la contribución directa para la planificación turística del cantón, a través del correcto aprovechamiento de los recursos, para lo cual se considera la caracterización del sistema turístico, que es la teoría más fuerte y desarrollada en el estudio del turismo como fenómeno, $\mathrm{y}$ ha sido ampliamente discutida. Cuervo (1967) plantea un enfoque sistémico del turismo, compuesto por nueve subconjuntos, que se dividen en subgrupos, que se puede relacionar con lo que hoy se conoce como catastro turístico. Este autor presupone que estos elementos interactúan respondiendo a una función de comunicación que caracteriza a un sistema. Por otro lado, Neil Leiper plantea cuatro aspectos básicos en el sistema turístico, el turista como actor del sistema, los elementos geográficos que componen la localidad con los espacios: emisor, receptor, el espacio de tránsito y la industria turística, que son quienes se ven involucrados en la oferta del producto turístico (Abarca, 2016).

Es necesario, además, considerar a las modalidades turísticas como el centro de los resultados esperados, porque son de suma importancia en el desarrollo turístico, como expresan Ibáñez \& Cabrera (2011), ya que el turismo no implica al turista que se desplaza como lo señalan los anteriores autores, sino más bien a las motivaciones que estos tienen para que se proceda a realizar el desplazamiento hacia un sitio que no es de su cotidianidad. Es así como surgen las modalidades turísticas que se identifican con prácticas que diferencian las motivaciones y factores de atracción, que constituyen variables determinantes para llevar a cabo esta actividad. No solamente estos aspectos configuran las modalidades, sino que también se toman en cuenta el tiempo disponible y la organización del espacio (territorio) (Palomeque, 1993). El diagnóstico turístico de la localidad se basa en la evaluación del sistema turístico para impulsar esta actividad en el cantón; además se debe considerar y determinar en qué ecosistemas se lleva a cabo la actividad, así como también la caracterización de las expresiones culturales y la idiosincrasia de los moradores del territorio.

\section{Materiales y métodos}

\subsection{Area de estudio}

El cantón Pedro Vicente Maldonado se encuentra en el noroccidente de la provincia de Pichincha. Cuenta con una superficie de $656,5 \mathrm{~km}^{2}$ y una altitud de $620 \mathrm{~m}$ s.n.m. Limita al norte con la provincia de Imbabura, al sur con el cantón San Miguel de Los Bancos y la provincia de Santo Domingo de los Tsáchilas, al este con el cantón San Miguel de Los Bancos y el Distrito Metropolitano de Quito; al oeste con el cantón Puerto Quito (Instituto Espacial Ecuatoriano, 2014). Además, cuenta con una parroquia urbana (Pedro Vicente Maldonado) que se encuentra dividida en 26 recintos (Gobierno Provincial de Pichincha, 2017). Su población, según el Instituto Espacial Ecuatoriano (2014), es de 12.924 habitantes, de los cuales 5.561 se localizan en el área urbana; de estos 2.753 son hombres y 2.808 son mujeres, mientras que el área rural cuenta con 7.363 habitantes: 3.982 hombres y 3.381 mujeres. 


\subsection{Metodología}

La investigación tiene un enfoque mixto de tipo descriptivo, la información se sustenta en la revisión bibliográfica de fuentes primarias y secundarias, bajo el paradigma emergente, el método cualitativo permite obtener información mediante la observación de campo y la técnica de la entrevista. Por otro lado, con el método cuantitativo se recopila datos a través de la encuesta. Las herramientas cualitativas aplicadas durante la investigación son: la ficha de relevamiento turístico cantonal (Cabanilla, 2013), la matriz de inventario y jerarquización de atractivos turísticos del Ministerio de Turismo (MINTUR), la ficha de clasificación de ecosistemas del Ministerio del Ambiente (MAE), la ficha de registro de empresas, elaborada por la Empresa Metropolitana de Quito con ligeras modificaciones, además se considera los establecimientos registrados en el Catastro Nacional (Ministerio de Turismo, 2019) y finalmente se aplica la ficha etnográfica a la población del lugar (Guerrero, 2002)

La herramienta cuantitativa es la encuesta, que se establece en función del número de visitantes nacionales que ingresaron al cantón, dato que se refleja en la plataforma GEOVIT del Ministerio de Turismo en el año 2018. En este sentido, se calcula el tamaño de la muestra definido como un subconjunto de elementos que, en esencia, pertenecen a este conjunto delimitado en sus necesidades del que es conveniente extraer muestras representativas de un todo (Behar, 2008). Se utiliza el muestreo aleatorio simple, pues se considera la forma más común de obtener una muestra. La fórmula a emplearse es la siguiente:

$$
n=\frac{N}{\left(1+N e^{2}\right)}
$$

Donde:

$$
\begin{aligned}
& \mathrm{N}=\text { Población } \\
& \mathrm{e}=\text { Error }(0,5) \\
& \mathrm{n}=\text { Tamaño de la muestra } \\
& n=\frac{95566}{\left[1+95566(0.5)^{2}\right]}=100
\end{aligned}
$$

La encuesta fue dirigida a los visitantes del cantón Pedro Vicente Maldonado, tomando en cuenta un rango de edad de 18 a 45 años.

\section{Resultados}

Entre las causas de la problemática que se investiga, está la escasa planificación del territorio, por lo que se considera analizarlo a través del sistema turístico y su dinámica en la localidad, bajo el modelo propuesto por Cristina Varisco (2013), quien establece que dicho sistema está compuesto por subsistemas como: la demanda turística, la oferta turística que se divide en primordial y complementaria, la infraestructura, que son todos los servicios básicos para el desarrollo de la actividad turística, la superestructura que está integrada por los organismos públicos y privados que tienen por objetivo coordinar el territorio turístico y, por último, pero no menos importante, la comunidad receptora, considerada un subsistema en esta investigación por los autores.

\subsection{Oferta turística primordial}

Según Varisco (2013) ésta se encuentra integrada por los recursos turísticos, que son elementos de cultura o naturaleza. En esta investigación se relacionan también con las motivaciones para identificar modalidades turísticas. Los resultados encontrados mediante la aplicación de la matriz de inventario y jerarquización de atractivos del Ministerio de Turismo y la ficha de identificación de ecosistemas son los presentados a continuación.

En la Tabla 1 se observa la jerarquización de los atractivos naturales más representativos del cantón PVM, se evidencia que la ponderación se encuentra entre 10 y 35 puntos, por lo cual pertenecen a la jerarquía I. Dichos recursos turísticos naturales están ubicados en ecosistemas de bosque siempreverde, piemontano, específicamente bosque húmedo y matorral húmedo; en este sentido, la variedad de estos recursos permite que el territorio tenga potencial para practicar la modalidad de ecoturismo.

Tabla 1. Clasificación de atractivos naturales por tipo/subtipo, ecosistema y jerarquía

\begin{tabular}{cclc}
\hline $\begin{array}{c}\text { Nombre } \\
\text { del atractivo }\end{array}$ & $\begin{array}{c}\text { Tipo } \\
\text { /Subtipo }\end{array}$ & Ecosistema & Jerarquía \\
\hline $\begin{array}{c}\text { Cascada } \\
\text { Salto del Tigre }\end{array}$ & $\begin{array}{c}\text { Ríos }- \\
\text { Cascada } \\
\text { Ríos }-\end{array}$ & $\begin{array}{c}\text { Bosque } \\
\text { húmedo }\end{array}$ & I \\
Ráo Caoní & Río & húmedo & I \\
& Ríos - & $\begin{array}{c}\text { Matorral } \\
\text { húmedo }\end{array}$ & I \\
Cascada Ayalir & $\begin{array}{c}\text { Cascada } \\
\text { Ríos } \\
\text { Río Los Canelos }\end{array}$ & $\begin{array}{c}\text { Matorral } \\
\text { húmedo }\end{array}$ & I \\
& $\begin{array}{c}\text { Río } \\
\text { Ríos }-\end{array}$ & $\begin{array}{c}\text { Bosque } \\
\text { húmedo }\end{array}$ & I \\
\hline
\end{tabular}


Los recursos culturales que se muestran en la Tabla 2 han permitido a las autoridades del cantón planificar el potencial para la tendencia de turismo religioso, ya que según María Sandoval (2019), técnica de turismo del cantón, cada iglesia "cuenta con diversos objetos y reliquias religiosas que poseen gran valor patrimonial". Cabe destacar que no se han considerado recursos artesanales y gastronómicos ya que estos son tomados en cuenta en el subsistema comunidad. Por otro lado, los recursos naturales y culturales en el área son más potenciales que reales, debido a que se realiza turismo de manera informal, según López Olivares (2001) cuando la oferta se da de manera espontánea y sin mayor estructura organizativa los recursos se mantienen como tal y no logran ser un producto turístico, que es lo que pasa en la zona.

Tabla 2. Clasificación de atractivos culturales por tipo/subtipo, ecosistema y jerarquía

\begin{tabular}{llll}
\hline Nombre del atractivo & Tipo/Subtipo & Ecosistema & Jerarquía \\
\hline Iglesia La Celica & Arquitectura - Histórica/vernáculo & - & I \\
Iglesia de Andoas & Arquitectura - Histórica/vernáculo & - & I \\
Iglesia "Nuestra Señora del Cisne" & Arquitectura - Histórica/vernáculo & - & I \\
Parque de Andoas & Arquitectura - Espacio público & - & I \\
Parque Central Benjamín Peralvo & Arquitectura - Espacio público & - & I \\
& Realizaciones técnicas y científicas - Bosque hú- & I \\
Reserva Ecológica Mangaloma & Centro de exhibición de flora y fauna & medo & \\
\hline
\end{tabular}

\subsection{Oferta complementaria}

Otro de los aspectos a considerar es el inadecuado desarrollo de empresas; la oferta turística complementaria en donde se encuentran todos aquellos servicios que apoyan al desarrollo de la actividad turística (Cabarcos, 2006), y el conjunto de facilidades y servicios que utilizan los turistas para desplazarse, permanecer y realizar en el destino todo lo anhelado (Quesada, 2007) ameritan revisión en función de conocer si se encuentran dentro del mar- gen legal, para la obtención de resultados se aplicó la ficha de empresas.

En la Tabla 3 se establece, según la información del catastro del Ministerio de Turismo, el número de establecimientos que ofrecen servicios en la provincia de Pichincha, por cantón. Se evidencia que el cantón Pedro Vicente Maldonado posee únicamente 17 establecimientos, los mismos que no representan ni el $1 \%$ con relación a toda la provincia (Figura 1).

Tabla 3. Número de establecimientos por cantón, provincia de Pichincha

\begin{tabular}{lll}
\hline \multicolumn{3}{c}{ Número de empresas } \\
\hline Cantones & MINTUR \\
D.M. Quito & 4.380 \\
& Rumiñahui & 370 \\
& S.M. Los Bancos & 162 \\
Mejía & 161 \\
Cayambe & 152 \\
& Puerto Quito & 38 \\
& Pedro Moncayo & 28 \\
P. Vicente Maldonado & $\mathbf{1 7}$ \\
\hline
\end{tabular}




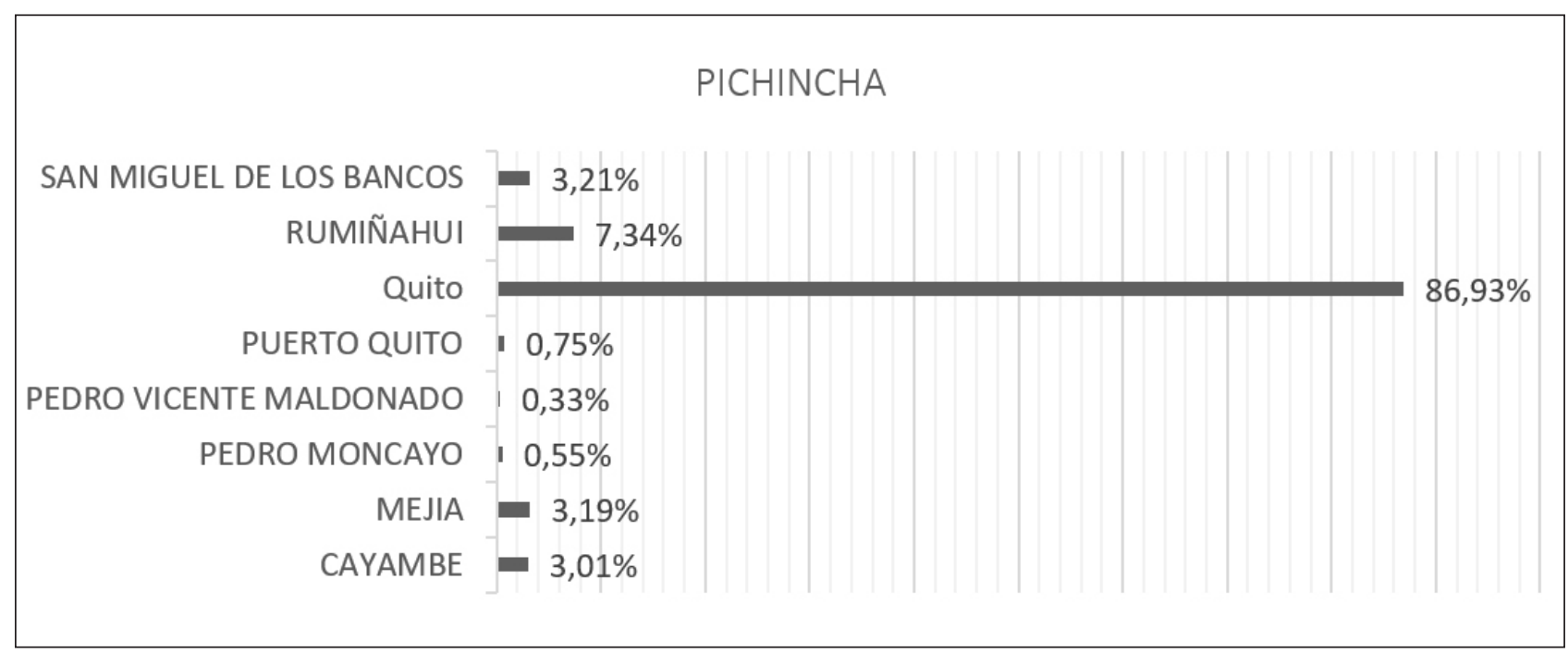

Figura 1. Porcentaje de actividades por cantón.

Según el Ministerio de Turismo, como se presenta en la Tabla 4, existen 12 empresas dedicadas al alojamiento y 5 de alimentos y bebidas, mientras que en la visita in situ se consignaron 12 empresas de alojamiento y 7 de alimentos y bebidas, lo que muestra una discrepancia en la información y lleva a considerar que existen empresas que no se encuentran registradas en el catastro. La actividad de operación e intermediación no cuenta con un solo establecimiento, sin embargo, en la aplicación de la entrevista a Henry Cárdenas (2019), guía local del cantón, certificado por el Ministerio de Turismo, se establece que "existe una asociación de guías locales que están trabajando para la implementación de una agencia turística en el territorio", lo que hace pensar, nuevamente, que la práctica del turismo en la zona no está regulada ni organizada.

Tabla 4. Número de establecimientos por actividad, cantón PVM

\begin{tabular}{lcc}
\hline \multicolumn{3}{c}{ Número de empresas } \\
\hline \multicolumn{1}{c}{ Actividad } & Catastro MINTUR & In situ \\
\hline Alojamiento & 12 & 12 \\
Alimentos y bebidas & 5 & 7 \\
Operación e intermediación & 0 & 0 \\
Transporte turístico & 0 & 0 \\
Intermediación & 0 & 0 \\
\hline Total & 17 & 19 \\
\hline
\end{tabular}

\subsection{Demanda}

La demanda turística constituye un elemento fundamental en el fenómeno turístico. Está constituida por consumidores directos e indirectos que satisfacen sus motivaciones consumiendo los bienes y servicios que se promocionan; comprende un grupo heterogéneo de personas con diferentes características sociodemográficas, motivaciones y experiencias, que influenciadas por sus intereses y necesidades particulares, desean, pueden y están dispuestos a disfrutar del turismo (Socateli, 2013). En este contexto se analiza el perfil del turista en el cantón Pedro Vicente Maldonado, en función de la motivación y preferencia de visita.

Los resultados que se obtuvieron a partir de la aplicación de la encuesta a los visitantes del cantón (100), se describen a continuación. Con la información recolectada se determina el perfil del turista del cantón Pedro Vicente Maldonado (Figuras 2, 3 y 4), el mismo que es de género 
masculino y femenino, de 18 a 30 años de edad, solteros, con un nivel de ingresos de $\$ 0$ a $\$ 500$, dispuestos a pernoctar de 1 a 3 días para realizar actividades turísticas.

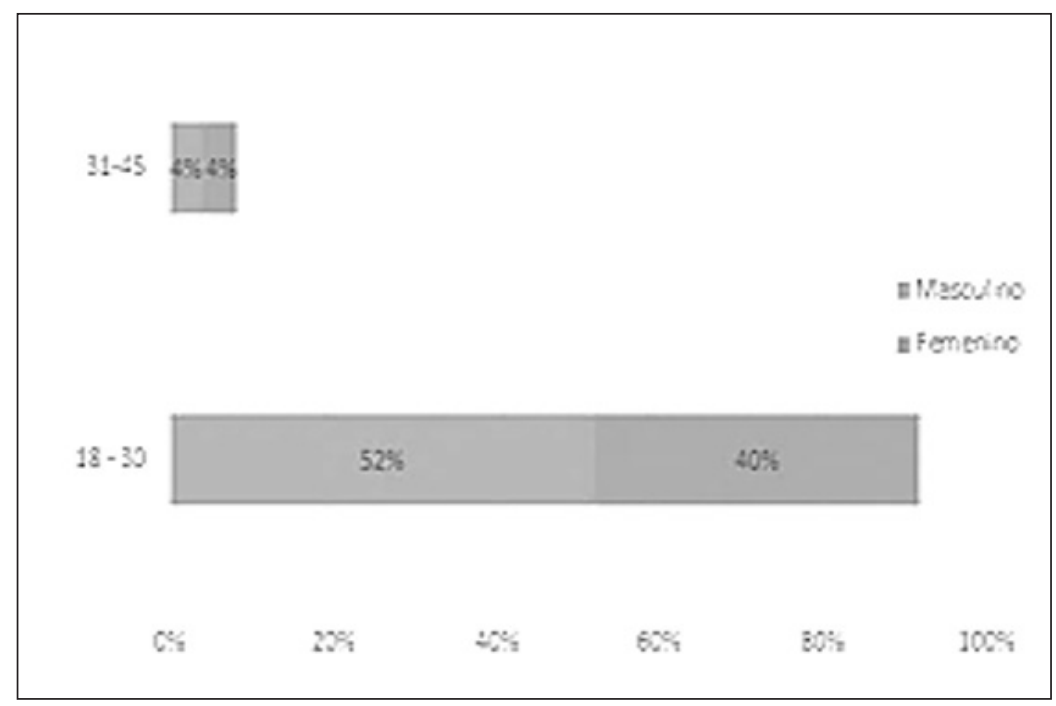

Figura 2. Visitantes según género y edad.

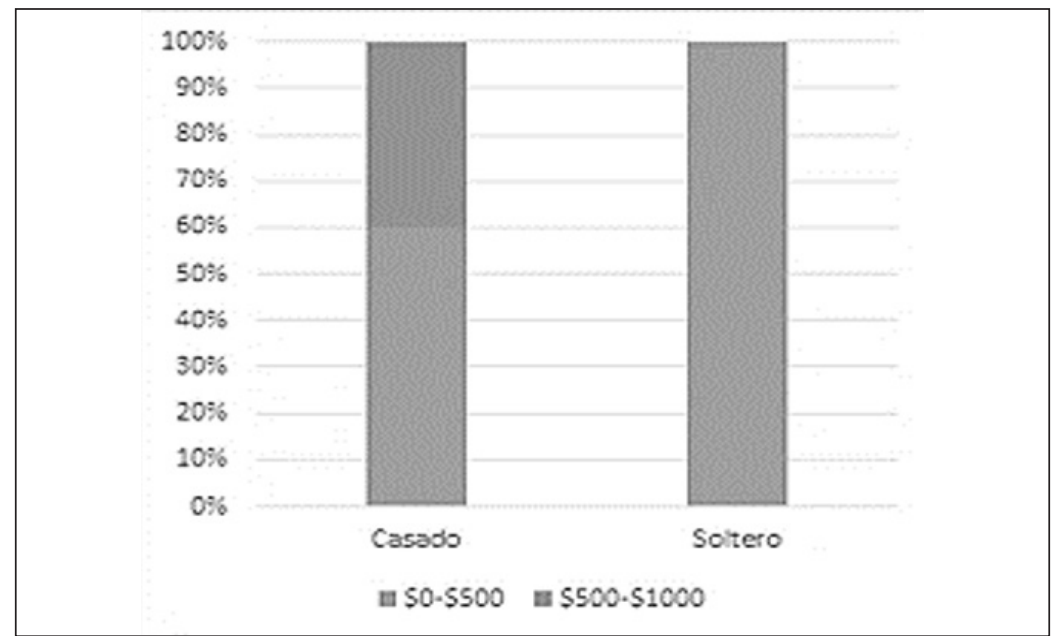

Figura 3. Nivel de ingresos/estado civil.

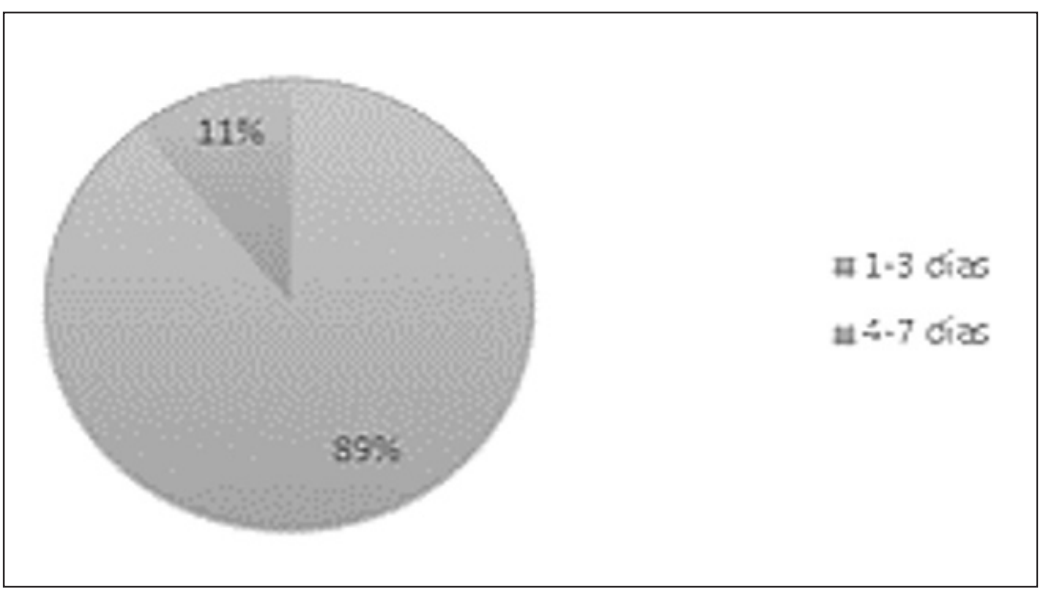

Figura 4. Días de estadía. 
De acuerdo con la aplicación de la herramienta, los resultados demuestran (Figura 5) que no existe una relación entre la modalidad turística y el género, por lo tanto, se evidencia que la modalidad de preferencia para los dos géneros es el ecoturismo. Por otro lado, el turismo religioso para ambos géneros tiene poca expectativa.

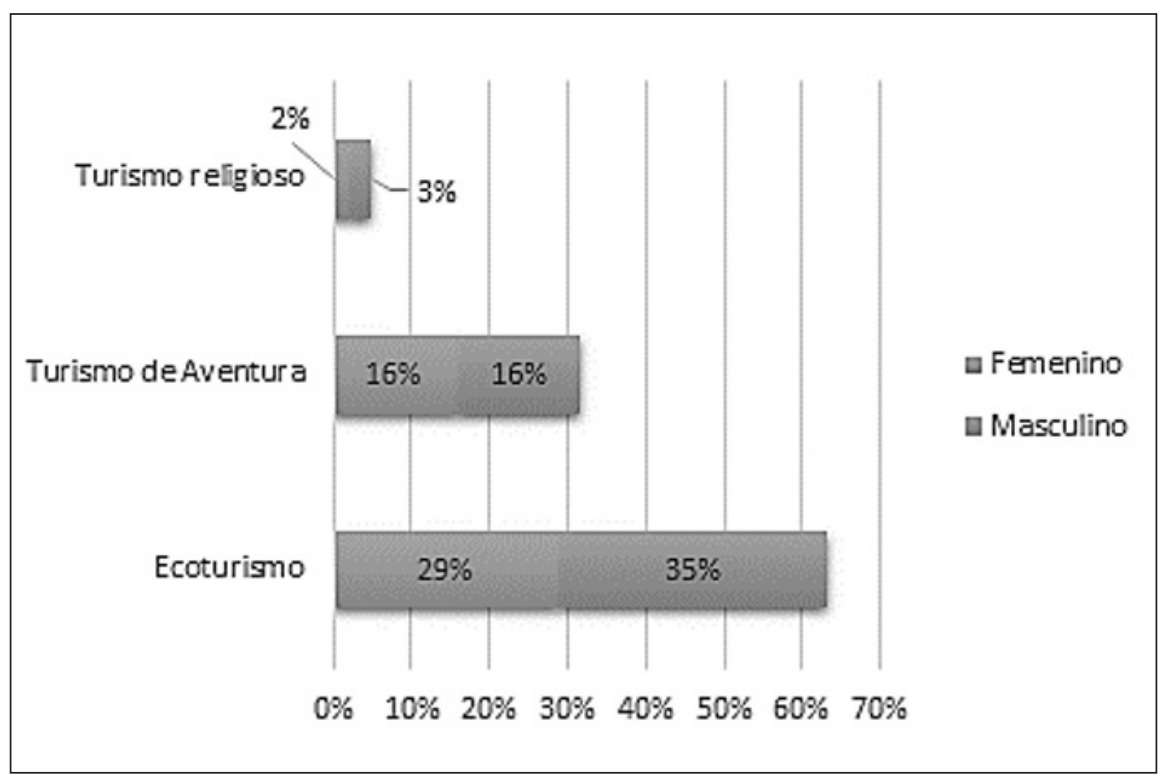

Figura 5. Modalidad de preferencia según género.

Como se observa en la Figura 6, el género no influye de manera determinante en las actividades que se realizan, por lo que se podría ofertar toda esta variedad de actividades o tendencias sin consideraciones de género ya que están alineadas al rango de edad correspondiente al perfil del visitante.

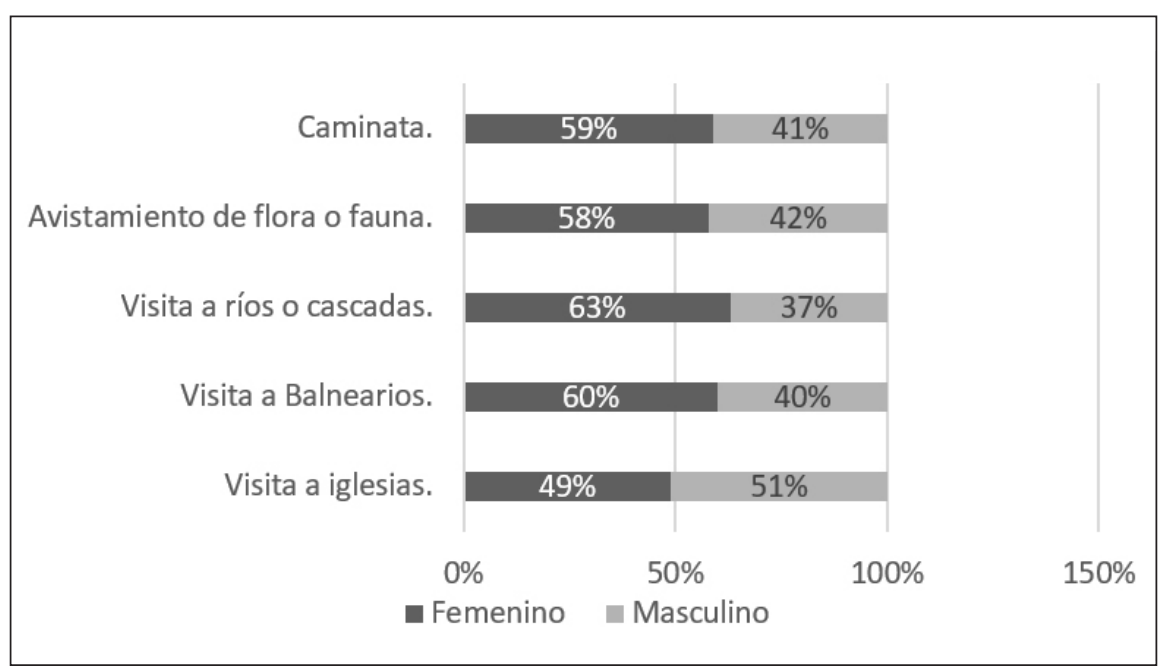

Figura 6. Actividades turísticas según género.

En la Figura 7, se muestra que los turistas del cantón en su mayoría prefieren realizar cualquiera de las actividades turísticas en compañía de amigos y familiares. Cabe señalar que las diferentes activi- dades propuestas no tienen una diferencia amplia entre sí y por tanto, como se demostró en el gráfico anterior, todas las actividades son aceptadas o consideradas por el visitante. 


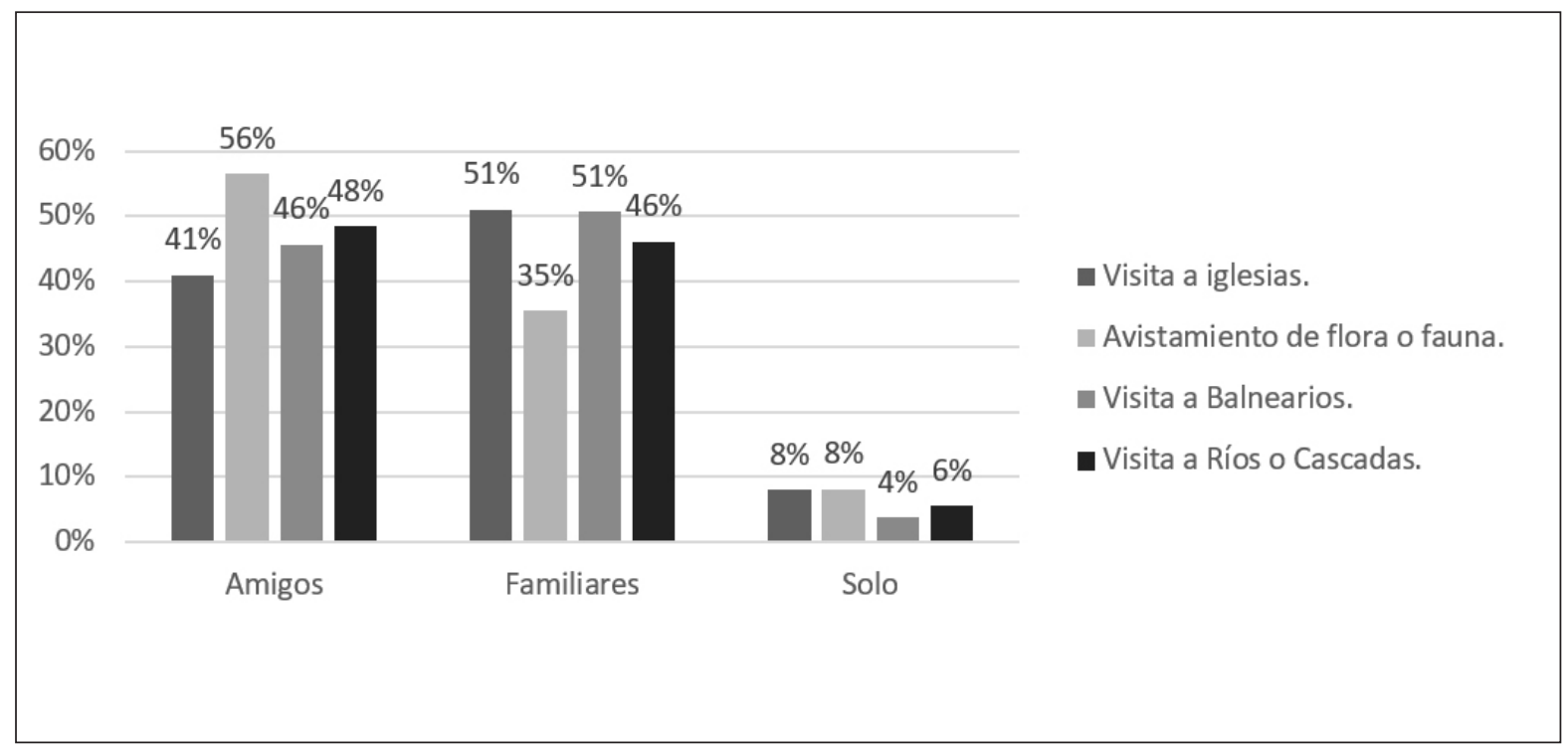

Figura 7. Actividades turísticas - Acompañamiento.

Como muestra la Figura 8 existe relación entre la modalidad y el acompañamiento. Se observa que la preferencia es realizar turismo religioso en compañía de familiares o solo; mientras que en el caso de los turistas que realizan turismo de aventura un elevado porcentaje lo hace con amigos. El ecoturismo, por otro lado, mantiene una situación homogénea en cuanto a la preferencia y la posibilidad de realizarlo solo o con familiares $\mathrm{y}$ amigos.

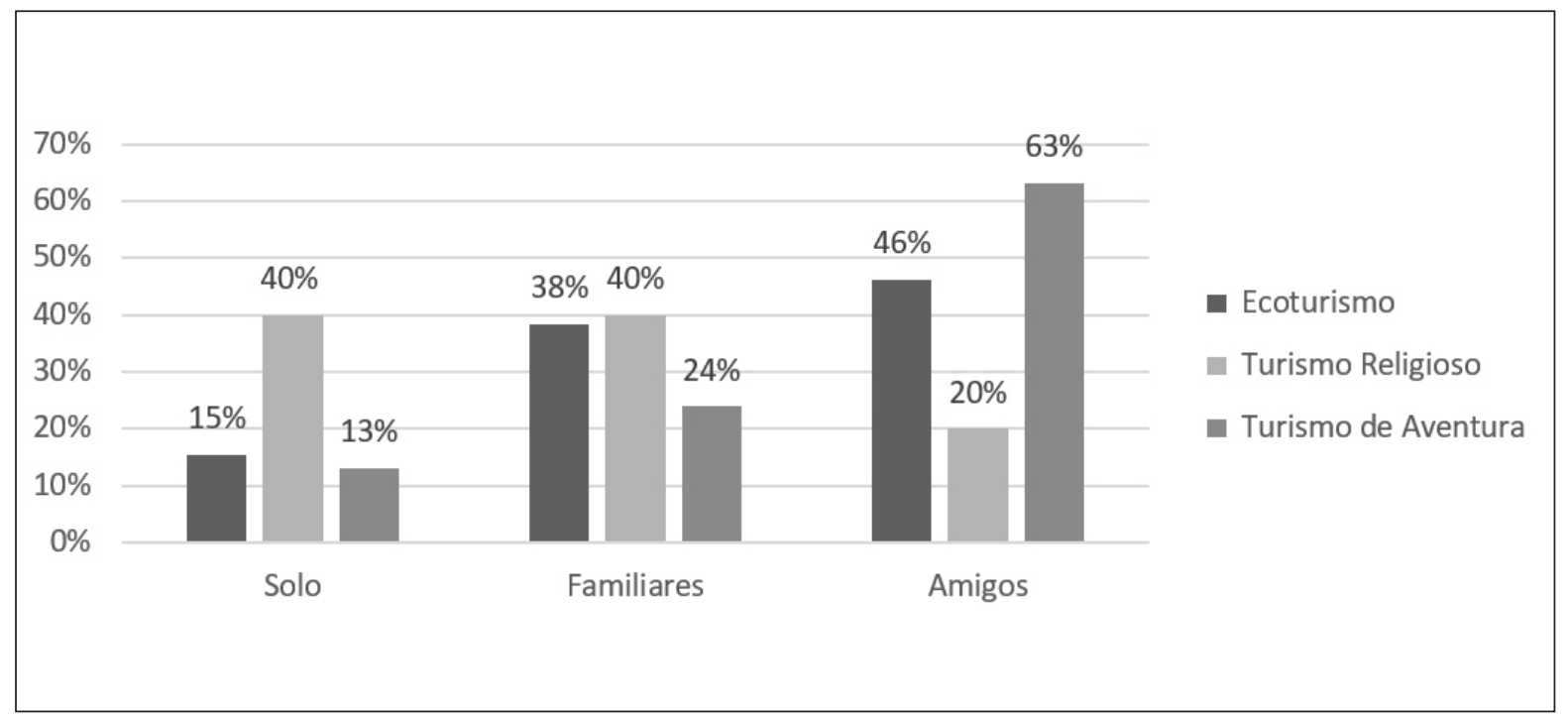

Figura 8. Modalidad turística - Acompañamiento.

Los datos que se muestran en la Figura 9 reflejan que los turistas, en su mayoría, han sido referenciados del lugar por amigos o familiares; en segundo lugar, han recibido información turística mediante redes sociales. Cabe recalcar que la in- formación compartida en redes sociales está administrada por empresas privadas; además existe promoción turística en la parte pública a través de la entrega de folletos y trípticos que son proporcionados en ferias. 


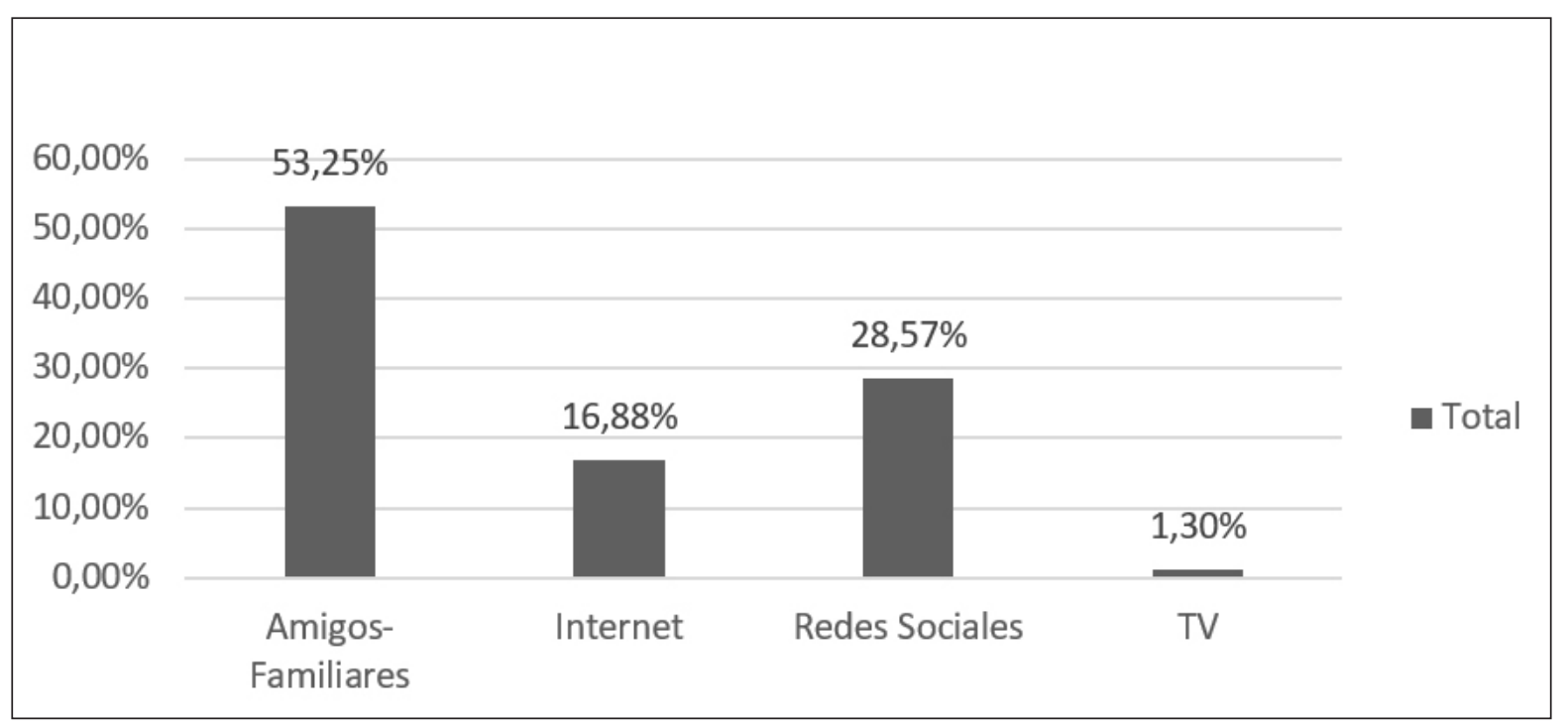

Figura 9. Medios de información turística.

\subsection{Infraestructura}

Es el conjunto de obras y servicios que permiten el desarrollo socioeconómico de un territorio y que el turismo utiliza para impulsar diversas actividades, entre las que se encuentran rutas de acceso, servicios de comunicación y equipamiento urbano (Universidad para la Cooperación Internacional, 2019). En cuanto a la infraestructura del cantón Pedro Vicente Maldonado (Tabla 5) se puede manifestar que cuenta con las condiciones mínimas para la ejecución de actividades turísticas; sin embargo, cabe recalcar que es necesario mejorar las rutas de acceso a los atractivos y la señalización en los mismos. Además, se debe considerar la necesidad de ampliar la red de seguridad y el acceso a internet.

Tabla 5. Infraestructura turística cantón PVM

\begin{tabular}{ll}
\hline \multicolumn{1}{c}{ Servicio } & \multicolumn{1}{c}{ Establecimiento / Detalle } \\
\hline Emergencias médicas & $\begin{array}{l}\text { Hospital y subcentro de salud. } \\
\text { Servicio de buena calidad. } \\
\text { Los accidentes de mayor complejidad son transferidos a Quito. }\end{array}$ \\
\hline Seguridad & $\begin{array}{l}\text { Bomberos } \\
\text { Policía Nacional } \\
\text { Cruz Roja } \\
\text { COE cantonal }\end{array}$ \\
\hline Servicios básicos & $\begin{array}{l}\text { Agua potable: Por sectores, excelente calidad. } \\
\text { Energía pública: Buen funcionamiento en todo el cantón. } \\
\text { Comunicación telefónica: Principales recintos. } \\
\text { Conexión a internet: No de acceso público. }\end{array}$ \\
\hline Educación & Acceso público y privado \\
\hline & Terrestre: E 28 \\
Rutas de acceso & \\
\hline
\end{tabular}




\subsection{Superestructura}

Se define como los "organismos oficiales y privados que se encargan de regular el sistema turístico" (Molina, 2000). En el caso de esta investigación se utiliza la pirámide de Kelsen (Figura 10) que Reyes
(2013) define como el ordenamiento jurídico de un conjunto de normas categorizadas jerárquicamente, a fin de considerar las instituciones que manejan dicha regulación y por tanto son actores indirectos, y la normativa vigente a considerarse para una propuesta turística.

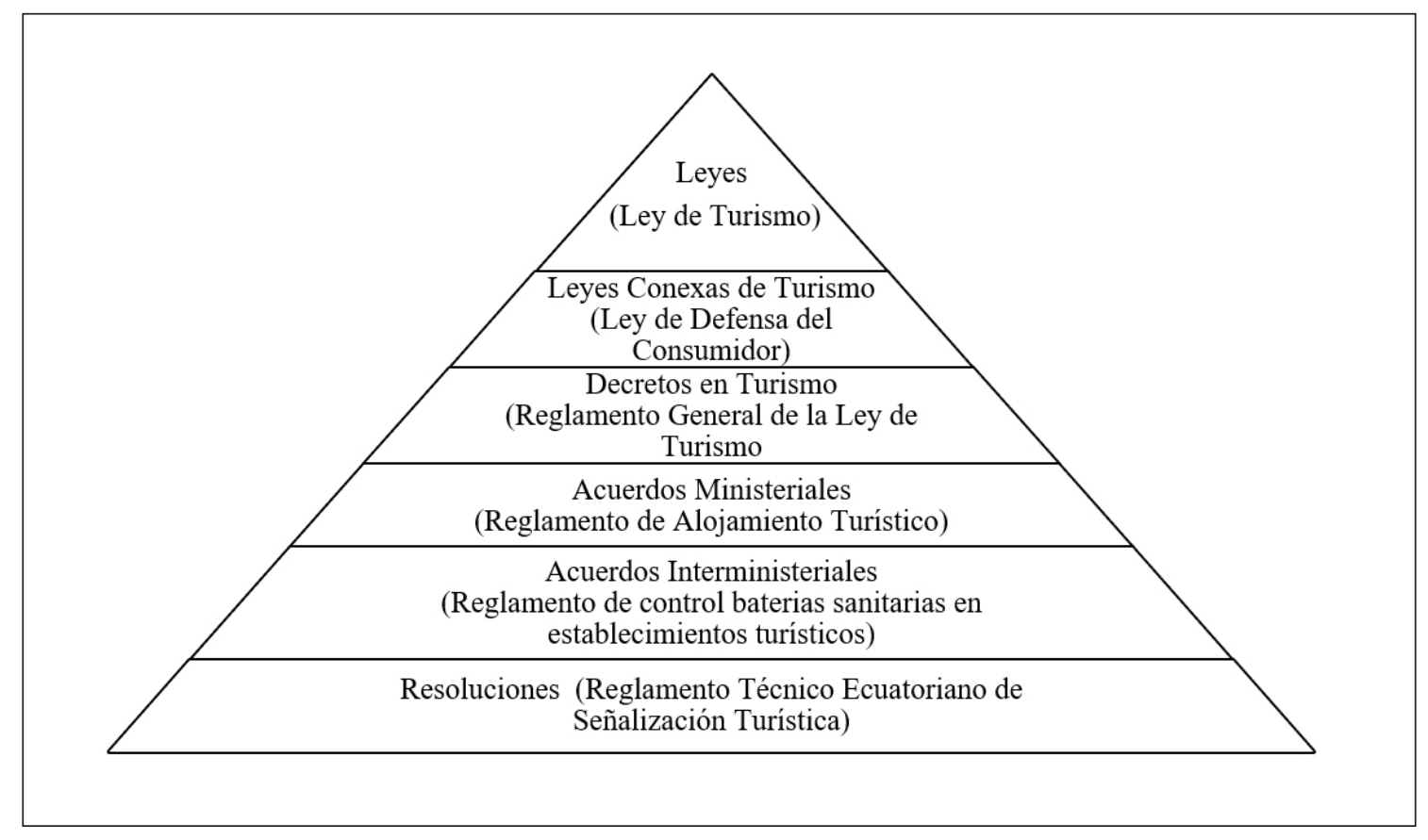

Figura 10. Pirámide de Kelsen. Normativa Ministerio de Turismo.

En el cantón PVM la ley que debe considerarse para la planificación turística es la Ley de Turismo que rige a todo el territorio ecuatoriano. Es substancial revisar leyes conexas como la Ley de Defensa del Consumidor, el Código Orgánico de Organización Territorial COOTAD; los decretos y acuerdos ministeriales e interministeriales que regulan las actividades turísticas son amplios y mejoran la prestación de los servicios, es importante revisar las resoluciones más actuales como la Resolución del 23 de marzo de 2016, en la que se faculta a los gobiernos autónomos descentralizados para el desarrollo de actividades turísticas.

En Pedro Vicente Maldonado, no se han desarrollado resoluciones cantonales en cuanto a la actividad turística, sin embargo, María Sandoval (2019), técnica de turismo, expresa que actualmente existen propuestas por aprobar y trabajar en la entidad municipal del territorio. Por tanto, las entidades que deben trabajar en conjunto para mejorar la gestión del turismo son el Ministerio de Turismo, Consejo Provincial de Pichincha y el Gobierno Autónomo Descentralizado de PVM.

\subsection{Comunidad receptora}

Según Varisco (2013), es la población local que no participa de manera directa en el resto de los subsistemas, pero tiene fundamental importancia para el desarrollo local, ya que hay determinados aspectos de la vida de los pueblos que caracterizan y condicionan su comportamiento tanto individual como colectivo e inciden de manera muy significativa en su desarrollo social y económico (Comisión Económica para América Latina, 1978). Las características tangibles e intangibles autóctonas de una población convertidas en patrimonio forman parte de la construcción del fenómeno turístico, de tal manera que el turista será capaz de asimilar el patrimonio del territorio visitado, haciéndose una idea de la identidad cultural del mismo (Cepeda, 2018). A continuación, en la Tabla 6 se muestran los aspectos culturales que potencialmente pueden ser aprovechados en el turismo, a partir de la aplicación de la ficha etnográfica. 
Tabla 6. Expresiones culturales del cantón PVM

\begin{tabular}{ll}
\hline \multicolumn{1}{c}{ Expresión cultural } & \multicolumn{1}{c}{ Nombre de la manifestación } \\
\hline Fiestas tradicionales & $\begin{array}{l}\text { Cantonización de Pedro Vicente Maldonado (15 de enero) } \\
\text { Actividades de fortalecimiento de la integración e identidad Pedro vicentina (5 al } \\
20 \text { de junio) } \\
\text { Expo feria ganadera, agrícola, agroindustrial, artesanal, turística y comercial } \\
\text { (agosto) }\end{array}$ \\
\hline Gastronomía & $\begin{array}{l}\text { Tilapia frita } \\
\text { Ceviche de palmito }\end{array}$ \\
\hline Juegos tradicionales & Fiestas taurinas \\
\hline Vestimenta & Ganaderos montubios (utilizada en festividades) \\
\hline
\end{tabular}

Estas expresiones son muy consideradas por la comunidad Pedro vicentina y celebran con mucho fervor sus festividades, por ello se considera que con una correcta comercialización son potenciales atractivos. Como un elemento agrega-

Figura 11. Pirámide poblacional de edades PVM.

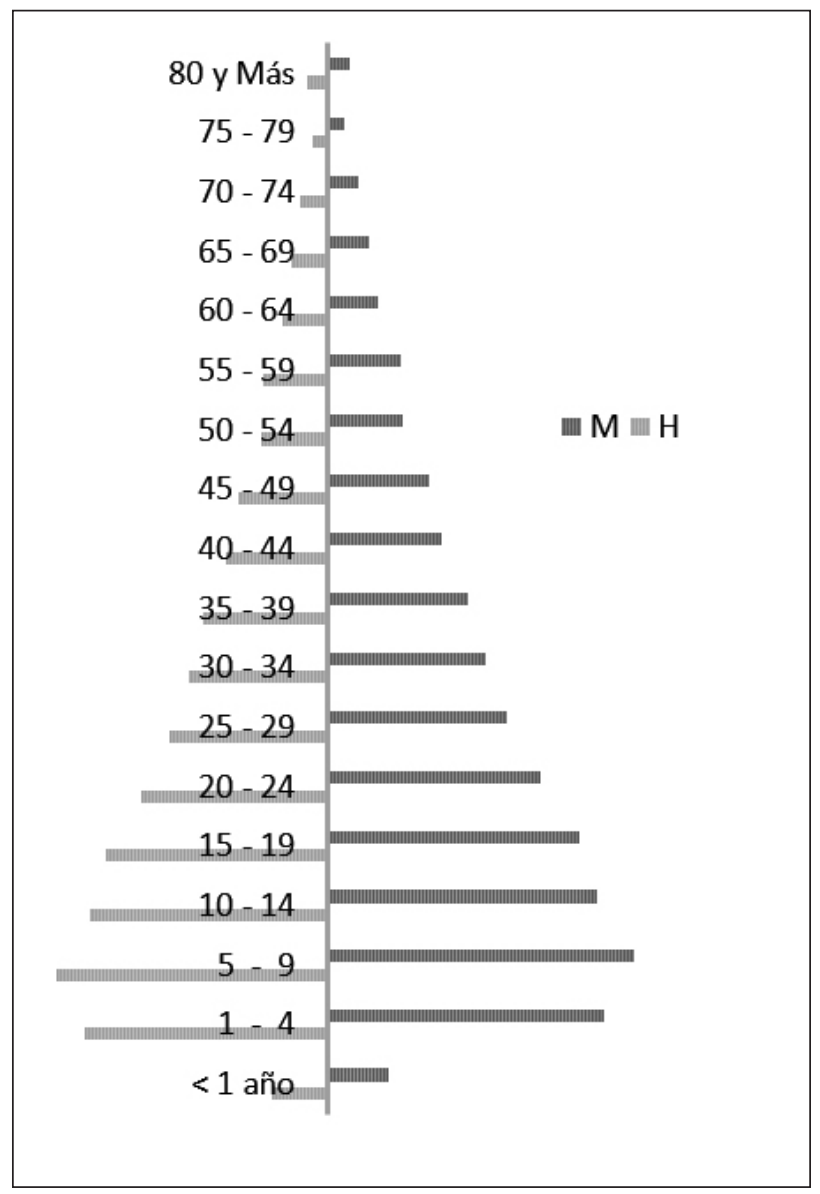

do dentro del análisis de la población se toma en cuenta el crecimiento y la estructura etaria de la misma según el INEC (2010) en el último censo, como se muestra en la Figura 11 y en la Tabla 7 de la siguiente forma:

\begin{tabular}{|c|c|c|c|}
\hline \multicolumn{4}{|c|}{ Censo INEC 2010} \\
\hline Edad & Hombres & Mujeres & Total \\
\hline$<1$ año & -162 & 185 & 347 \\
\hline $1-4$ & -724 & 824 & 1.548 \\
\hline $5-9$ & -805 & 915 & 1.719 \\
\hline $10-14$ & -706 & 803 & 1.509 \\
\hline $15-19$ & -661 & 751 & 1.412 \\
\hline $20-24$ & -556 & 632 & 1.189 \\
\hline $25-29$ & -471 & 535 & 1.006 \\
\hline $30-34$ & -413 & 470 & 884 \\
\hline $35-39$ & -370 & 421 & 791 \\
\hline $40-44$ & -301 & 342 & 643 \\
\hline $45-49$ & -265 & 301 & 566 \\
\hline $50-54$ & -199 & 226 & 425 \\
\hline $55-59$ & -192 & 218 & 410 \\
\hline $60-64$ & -131 & 149 & 280 \\
\hline $65-69$ & -109 & 124 & 233 \\
\hline $70-74$ & -80 & 91 & 171 \\
\hline $75-79$ & -45 & 51 & 96 \\
\hline 80 y Más & -57 & 65 & 123 \\
\hline TOTAL & -6.248 & 7.102 & 13.350 \\
\hline
\end{tabular}

Tabla 7. Diagrama de estructura de edades PVM 
La mayoría de la población de Pedro Vicente Maldonado es joven, lo que es beneficioso para el turismo ya que se mantiene activa y se puede trabajar en la forma- ción de cultura e identidad Pedro vicentina, en el aprovechamiento de los recursos que se encuentran dentro del territorio y el correcto uso de los mismos (Tabla 8).

Tabla 8. Identificación cultural de los pobladores

\begin{tabular}{lll}
\hline \multicolumn{1}{c}{ Datos generales } & \multicolumn{1}{c}{ Característica } & \multicolumn{1}{c}{ Identificación } \\
\hline \multirow{3}{*}{ Organización social } & Grupo étnico & Mestizo \\
& Tipología familiar & Monogamia \\
& Sociedad tradicional & Cabildo \\
& Religión & Católica / Evangélica \\
& Actividad económica & \\
Organización económica & Destino producción & Agricultura y ganadería \\
& agrícola & \\
& Alimentación & Verde y yuca \\
Organización cultural & Estilo de vida & Rural campestre \\
& Actitud ante la vida & Positiva \\
\hline
\end{tabular}

La idiosincrasia según Sánchez (2012) es la manifestación de la cultura, centrada en un grupo de la sociedad más bien homogéneo, con características y factores comunes, que generalmente se dan por cercanía geográfica, por lengua o nacionalidad. Los pobladores Pedro vicentinos tienen un modo de vida rural campestre como se muestra en la tabla 8 , debido a que la mayoría de su población son agricultores y ganaderos, como lo afirma el Instituto Nacional de Estadística y Censos (2010) con un 50,7\% de actividades realizadas por los pobladores. Se observa un gran apego religioso debido a que la población cuenta con reliquias religiosas de gran valor. Los habitantes tienen disposición positiva para promover la actividad turística, aunque carecen de conocimiento y apoyo técnico.

Una vez analizados todos los subsistemas se puede concluir el diagnóstico, como se muestra en la Tabla 9 la cual utiliza una escala de Likert en la que se establece una valoración cuantitativa y cualitativa para definir la situación actual de la localidad (Tabla 10).

Tabla 9. Diagnóstico general con base en la teoría del sistema turístico

\begin{tabular}{|c|c|c|c|c|c|c|c|}
\hline Subsistema & Resultado Investigación & $\begin{array}{c}\text { MA } \\
\text { (5) }\end{array}$ & $\begin{array}{c}\text { A } \\
\text { (4) }\end{array}$ & $\begin{array}{l}\text { Ma } \\
\text { (3) }\end{array}$ & $\begin{array}{l}\text { PA } \\
\text { (2) }\end{array}$ & $\begin{array}{c}\text { I } \\
\text { (1) }\end{array}$ & Observación \\
\hline Oferta & $\begin{array}{l}6 \text { RC Jerarquía I, 1bosque } \\
\text { húmedo. } \\
5 \mathrm{RN} \text { - Jerarquía I, } 2 \\
\text { bosque húmedo } \\
3 \text { matorral húmedo. } \\
\text { Alojamiento } 12 \\
\text { establecimientos } \\
\text { Alimentación } 9 \\
\text { establecimientos } \\
\text { Operadora turística } 0 \\
\text { establecimientos }\end{array}$ & & & $\mathrm{X}$ & & & $\begin{array}{l}\text { El cantón cuenta con } 11 \text { atractivos los } \\
\text { cuales son de jerarquía baja. Hay que } \\
\text { trabajar mucho en potencializarlos. } \\
\text { Los prestadores de servicio deben } \\
\text { mejorar sus instalaciones y capacitarse } \\
\text { en atención al cliente. Se debe considerar } \\
\text { la normativa. } \\
\text { Es importante generar una operadora } \\
\text { turística. }\end{array}$ \\
\hline
\end{tabular}




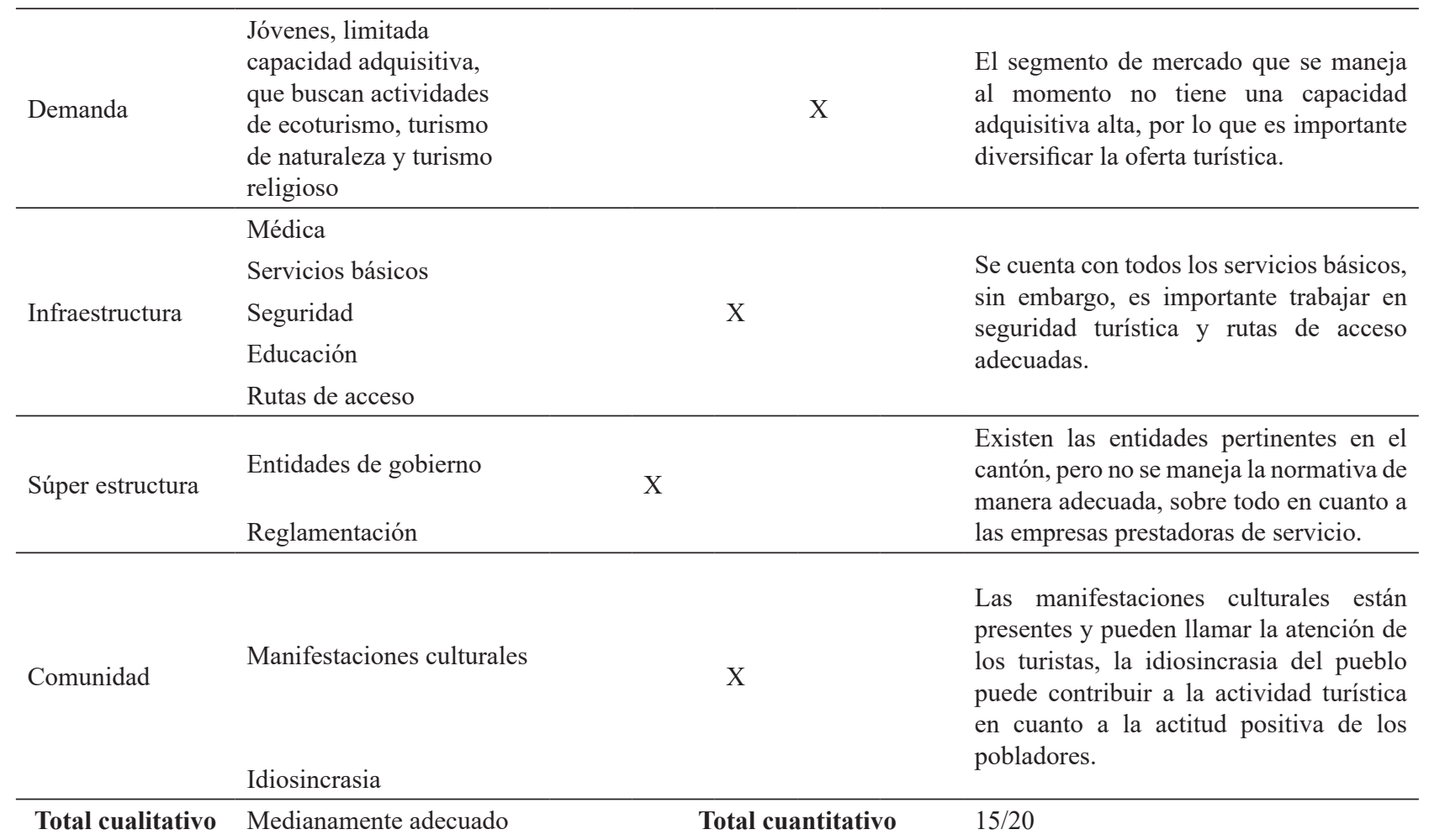

Fuente: Elaborado por el equipo investigador

Tabla 10. Escala de valoración (Likert)

\begin{tabular}{lc}
\hline \multicolumn{2}{c}{ Escala de valoración (Likert) } \\
\hline Rangos cualitativos & Valores cuantitativos \\
\hline Muy adecuado MA & $21-25$ \\
Adecuado A & $16-20$ \\
$\begin{array}{l}\text { Medianamente } \\
\text { adecuado Ma }\end{array}$ & $11-15$ \\
Poco adecuado PA & $6-10$ \\
\hline
\end{tabular}

Según el diagnóstico obtenido en cuanto al desarrollo del sistema turístico en PVM (potencial turístico), es medianamente adecuado para ejecutar actividades turísticas, ya que para potenciar el turismo se hace necesario la creación de un marco regulatorio adecuado que propicie y aliente esta actividad apoyado por las entidades gubernamentales y el sector privado, mejorar y regular los establecimientos prestadores de servicios, planificar de mejor manera la infraestructura para poder hacerla de uso turístico, incluir a la comunidad en todas las actividades como actores directos, y tener inversión destinada al mercadeo. Cabe resaltar que este cantón se considera apropiado para realizar ecoturismo y turismo religioso, de acuerdo con las motivaciones de los turistas, no se deja de lado el turismo de aventura, sin embargo, es 
importante considerar que la inversión sería onerosa y amerita contar con la seguridad turística apropiada.

\section{Discusión}

Varias son las concepciones y maneras de analizar el sistema turístico. Autores citados como Cuervo (1967), Abarca (2016) y Varisco (2013) coinciden en el paradigma de la complejidad sistémica para el estudio del turismo, lo que permite establecer una situación diagnóstica. En esta investigación se considera importante el análisis de cada uno de los subsistemas desde la concepción de Varisco (2013), con el valor agregado de considerar a la comunidad receptora como un subsistema más.

Así, el primer subsistema a considerarse es la oferta en la que se encuentra el aspecto ambiental que toma en cuenta el análisis de los ecosistemas como recursos del turismo para una buena gestión, ya que se han demostrado las afectaciones directas e indirectas a los ecosistemas por la actividad turística (Ibarra, Gámez, \& Ortega, 2018). En el caso específico de PVM es importante discutir cómo el paisaje, que es uno de los elementos de territorio, debe mantener sus principales funciones (homeóstasis y educación), por lo que se hace necesario plantear estrategias de gestión territorial sostenibles, que permitan el mantenimiento de la biodiversidad, no solo desde la lógica escenográfica, sino también considerando la valoración de las funciones ambientales, al establecer un valor económico por un paisaje o un espacio específico. Por otro lado, en el ámbito turístico se debe tomar en cuenta que el paisaje en sí es educador, ya que difunde valores propios de la localidad y se debe evitar introducir en los mismos mensajes artificiales o fuera de contexto con la realidad, tal como lo aseguran Floch \& Bru (2017).

Por otro lado, en la demanda, siguiente subsistema, es importante considerar la predilección de los turistas, quienes prefieren lugares rurales como el cantón PVM, en estas localidades según Abellán (2013) hay un protagonismo importante del paisaje, ya que se pretende el disfrute del medio ambiente, de allí la importancia de considerar la temática del paisaje, el cual debe cuidarse en la zona para evitar el deterioro del mismo con pérdida de actividades agrarias de la localidad, la cultura propia de la población, y el ambiente, el mismo que tiene un precio social basado en la potencialidad territorial, por lo que el paisaje se convierte en recurso y objeto de consumo.
La comunidad es un aspecto importante de discusión en esta investigación, pues todas sus características y representaciones colectivas confluyen en el paisaje, el mismo que según Font (1992) está fuertemente influenciado por la cultura, la cual en turismo permite a través de imágenes generar información y difundir un centro turístico, de ahí la importancia del paisaje en turismo. Para Peter Newby (1981) citado por Font (1992) es importante que la planeación turística impulse una descripción de los lugares turísticos con imágenes del paisaje haciéndolos más reales y culturalmente atrayentes. Ya que el paisaje no es solo el área geográfica rural, es la amalgama entre el entorno, la gente, la cultura y sus tradiciones. Por tanto, es importante dentro de la planeación territorial y de turismo considerar métodos de evaluación del paisaje. En esta investigación se consideran los dos métodos propuestos por Font: la evaluación de especialistas con diversas herramientas y las preferencias del público como se evidenció en los resultados.

Los recursos con los que cuenta el cantón Pedro Vicente Maldonado, hacen considerar diferentes modalidades de turismo que se pueden ejecutar en el territorio y la tendencia más adecuada que propicie la actividad turística. Según el análisis de esta investigación el potencial turístico de la localidad es medianamente adecuado y la modalidad con mayor probabilidad de generarse es el ecoturismo, ya que las condiciones naturales del cantón son aprovechables. Por otro lado, no se descarta la modalidad de turismo urbano con la tendencia de turismo cultural y naranja, basados en la religiosidad de este cantón y los bienes muebles con los que cuenta. La contribución de esta investigación radica precisamente en dar un punto de vista técnico que analice el problema identificado, en el que existe el planteamiento de realizar turismo de aventura según el PDOT (2015) o el nuevo direccionamiento de turismo religioso, según la entrevista a la especialista en turismo del cantón, por lo que desde una visión técnica con metodología investigativa se considera pertinente y viable la propuesta de ejecutar la modalidad de ecoturismo en la zona.

Para apoyar dicha propuesta, ya que el territorio está medianamente preparado para realizar actividad turística, es necesario evidenciar las necesidades y los problemas a resolver previo a realizar una planeación turística adecuada. Es importante transparentar la situación para tener una prospectiva clara, en la que se establezca que el turismo no es la salvación económica del cantón y mucho menos un eje estratégico; es una posibi- 
lidad de crecimiento para la comunidad, la cual tiene que estar acompañada de varias iniciativas públicas y privadas, pero no por esto se debe descuidar la actividad económica más importante de la zona (agricultura y ganadería) sino que debe ser otra actividad que se sume al fomento económico, a través de la trasformación del sistema productivo, la diversificación de la producción local, la generación de valor agregado y la conservación del ambiente (paisaje), como lo establece Díaz (2017) quien identifica el desarrollo local no solo en el ámbito económico sino también el en ámbito social, humano y ambiental.

\section{Conclusiones}

En el diagnóstico situacional de las modalidades y destinos turísticos del cantón Pedro Vicente Maldonado se concluye que el territorio es medianamente adecuado para la actividad turística, debido a que posee recursos naturales, en su mayoría ríos y cascadas; culturales, como iglesias y parques, los cuales, con una correcta planificación turística de los actores públicos y privados, pueden potenciar la modalidad de turismo ecológico y la tendencia de turismo religioso.

El cantón Pedro Vicente Maldonado cuenta con características que permiten el desarrollo de la modalidad de ecoturismo, debido a la variedad de recursos naturales que posee, sin embargo, es necesario mejorar la infraestructura para configurar los recursos como atractivos turísticos, que generen dinamización de flujos turísticos. Adicionalmente, se ha identificado a la tendencia de turismo religioso, debido al gran valor arquitectónico que poseen las iglesias de la localidad.

\section{Referencias}

Abarca, M. (2016). Propuesta de un modelo alternativo del sistema turístico. Escuela Superior Politécnica de Chimborazo Extensión Norte Amazónica de la República del Ecuador.

Abellán, F. C. (2013). La función del paisaje como recurso territorial turístico en zonas del interior. Observatorio Medioambiental, 16, 3754. https://doi.org/10.5209/rev_OBMD.2013. v16.43199
En la caracterización del sistema turístico del cantón se obtuvo que la planificación territorial es escasa, debido a que no se han desarrollado estrategias que permitan el aprovechamiento de los recursos de manera consciente e influir de manera positiva en la comunidad para el desarrollo de pequeños emprendimientos que involucren la actividad turística, por lo que no existen operadoras de turismo, y tampoco se ha manifestado la entidad pública a fin de que se cree una terminal de buses para uso turístico.

El turismo que se desarrolla en el cantón Pedro Vicente Maldonado, no se ve apoyado en su totalidad por los pobladores, debido a que la idiosincrasia de esta población en el aspecto económico se ve centrada en la actividades agrícola y ganadera, puesto que genera mejores beneficios, mientras que el impulso de las actividades turísticas no aporta mayor ingreso a la economía, por los factores anteriormente mencionados. Además, los actores que acaparan los beneficios de la actividad turística en el cantón son empresarios privados.

El paisaje es un componente importante dentro del territorio y permite, en la planeación turística, ofertar los recursos en sí. Por tanto, es importante valorar las funciones de dichos recursos, no solo su imagen. El paisaje está influenciado por la cultura y por los habitantes, de allí la importancia de considerar a la comunidad dentro de la valoración de un lugar para la actividad turística. Desde el punto de vista del turista el paisaje es una de las motivaciones más frecuentes para realizar turismo, y puede representar un constructo social que se aprecia de acuerdo a las características del ser humano, el paisaje en el cantón es el recurso de mayor valor y el cual debe aprovecharse al máximo de manera eficiente y con conciencia.

Behar, D. (2008). Metología de la Investigación. Cabo Verde: Edit. Shalom.

Cabanilla, E. (2013). Turismo comunitario: del diagnóstico al plan de negocios. Bahía Blanca-Argentina: Creative commons atribucióncompartir igual 3.0 Unported.

Cabarcos, N. (2006). Promoción y venta de servicios turísticos: comercialización de servicios turísticos. España: Ideas Propias. 
Cárdenas, H. (28 de junio de 2019). Operadoras turísticas en el cantón Pedro Vicente Maldonado. (K. Montenegro, \& A. Carabalí, entrevistadores)

Cepeda, J. (2018). Una aproximación al concepto de identidad cultural a partir de experiencias: El patrimonio y la educación. Universidad de Valladolid.

Comisión Económica para América Latina. (1978). La experiencia latinoamericana en los censos de población de 1970 y orientaciones para los censos de 1980. México: Biblioteca Naciones Unidas.

Cuervo, R. (1967). El turismo como medio de comunicación humana. México: Departamento de Turismo.

Díaz, G. (2017). Turismo y desarrollo local. Pasos. Revista de Turismo y Patrimonio Cultural, 15(2), 333-340. https://doi.org/10.25145/j.pasos.2017.15.021

Folch, R., \& Bru, J. (2017). Ambiente, territorio y paisaje. Valores y valoraciones. Barcelona: Barcino.

Font, J. N. (1992). Turismo, percepción del paisaje y planificación del territorio. Estudios Turísticos, $115,45-54$.

Gobierno Autónomo Descentralizado de Pedro Vicente Maldonado. (2015). Plan de Desarrollo y Ordenamiento Territorial. Quito: Gobierno Autónomo Descentralizado de Pedro Vicente Maldonado.

Gobierno Provincial de Pichincha. (29 de agosto de 2017). Pedro Vicente Maldonado. Obtenido de https://www.pichincha.gob.ec/cantones/pedro-vicente-maldonado

Guerrero, P. (2002). Guía etnográfica. Sistematización de datos sobre la diversidad y la diferencia de culturas. Quito: Editorial Abya-Yala.

Ibáñez, R., \& Cabrera, C. (2011). Teoría general del turismo. México: Serie Didáctica.

Ibarra, E., Gámez, A., \& Ortega, A. (2018). Impacto territorial del turismo en zonas prioritarias para la conservación y ecosistemas prioritarios de Baja California Sur, México. Sociedad y Ambiente, 17. https://doi.org/10.31840/sya. v0i17.1839

Instituto Espacial Ecuatoriano. (2014). Memoria técnica del cantón Pedro Vicente Maldonado. Quito: Senplades.

Instituto Nacional de Estadística y Censos. (2010). Población del cantón Pedro Vicente Maldonado. Quito: INEC.

López Olivares, D. (2001). La evaluación de los recursos territoriales turísticos de las comarcas del interior castellonense (Comunidad Valenciana). Investigaciones Geográficas, 25, 137-157.

Ministerio de Turismo. (2019). Consolidado Público Nacional. Quito: MINTUR.

Molina, S. (2000). Sistema turístico. México: Limusa.

Palomeque, A. (1993). Modalidades turísticas y tipologías de espacios turísticos. Papers de Turisme, 11, 49-64.

Quesada, R. (2007). Elementos del turismo. San José, Costa Rica: Universidad Estatal a Distancia.

Reyes, J. (2013). Diseño conceptual de un Sistema Experto Informático, como herramienta de apoyo en el proceso de elaboración de nuevas leyes, procedimientos, normas y reglamentos en el Ecuador. Universidad Andina Simón Bolívar.

Sánchez, N. (2012). Manifestaciones de la idiosincrasia colombiana en las prácticas del servicio. Universidad Piloto de Colombia.

Sandoval, M. (28 de junio de 2019). Situación actual del turismo en Pedro Vicente Maldonado. (K. Montenegro, \& A. Carabalí, entrevistadores)

Socateli, M. (2013). Demanda turística. Costa Rica: Universidad Estatal a Distancia.

Universidad para la Cooperación Internacional. (2019). Conceptos fundamentales del turismo. Obtenido de: http://www.ucipfg.com/Repositorio/MGTS/MGTS15/MGTSV15-07/semana3/ LS3.2.pdf

Varisco, C. (2013). Sistema turístico, subsistemas, dimensiones y conceptos transdisciplinarios. Mar del Plata: Universidad de Mar del Plata. 